\title{
The Correlation Analysis and Regression Analysis between China's Carbon Emissions and Transportation Industry
}

\author{
Mayila•Aizezi ${ }^{1,}$, , Ailijiang $• Y_{i b u l a y i n}{ }^{2, b}$ \\ ${ }^{1}$ Economics and Management college of Chang An university, Shaan xi Xi an, China \\ ${ }^{2}$ CCCC First High Way Consultants CO.,LTD. Shaan xi Xi an, China \\ a58204251@qq.com, b908910693@qq.com
}

\begin{abstract}
Keywords: carbon emissions freight turnover correlation analysis regression analysis
Abstract. In order to get the relationship between China's carbon emissions and transportation industry, we calculate the growth rate of carbon emissions and freight turnover based on the time series data from 1982 to 2014, showing them by the line chart. According to the change of the growth rate, carbon emissions growth rate can be divided into 3 sections, including accelerating growth section, stable growth section and decelerating growth section, the changing trend between freight turnover and carbon emissions is highly correlated. In the end we use the single variable linear regression to calculate the coefficient of the freight turnover, the conclusion is that the carbon emissions contributed by transportation industry is less than before gradually.
\end{abstract}

\section{Introduction}

With the development of World's economy, more and more countries are concerning with the energy consumption and environment pollution problems since 2000. China made a promise that the government would try it's best to reduce the emission of carbon dioxide in the future at the Copenhagen Climate Conference 2009.

Transportation is one of the industries which consuming energy so much, the proportion of the total carbon emissions caused by it is high. According to China Energy Statistical Yearbook and some other statistical data, the energy consumption growth rate of transportation industry is $7.5 \%$ more than the total energy consumption growth rate $5.9 \%$. The consumption growth rate of petroleum energy reach up to $10.1 \%$, at the same time the growth rate of carbon emissions is $7 \% \sim 8 \%$. Therefore transportation industry is the key to achieve the goal that is energy saving and emission reduction.

Large quantities of researches are concerning the relationship between low carbon and transportation industry. Alan Mckinnon (2007) considered the application of low carbon energy and the improvement of energy utilization efficiency can reduce the carbon emissions caused by freight transportation. Pascal Poudenx (2009) considered the ITS could increase the proportion of public transportation so that decrease the carbon emissions. FANG A (2008) considered that people would like to choose small and economical cars when the urban spatial density is increasing. Fengming Su put forward the method to improve transportation efficiency by technology and advanced management in order to reduce carbon emissions. Chen Fei established a model to estimate carbon emissions and set Shanghai as an example to calculate the carbon emissions not only from transportation but also the total. Most of researches are concentrate on reducing carbon emissions by improving transportation system to solve the problem that carbon emissions is heavy in transportation industry. But in this article we discussed the relationship between carbon emissions and transportation industry by different periods about carbon emissions in China.

\section{The total carbon emissions in China}

Global warming is the result of human's activities, especially the greenhouse gas carbon dioxide produced from fossil fuel caused this problem. So the carbon emissions in this article is that produced from fossil fuel like coal, petrol and nature gas. 
So far, China hasn't collected the data about carbon emissions, the data in this article is from the research of Guoquan $\mathrm{Xu}$ who estimated the quantity of carbon emissions in China. The estimating formula is as follows:

$$
Q=\sum_{i} M \times S_{i} \times C_{i}
$$

$Q$ - The total carbon emissions in a year

$M$ - The total energy consumption (standard coal) calculated by coal consumption for electricity generation

$S_{i}$ - The consumption ratio of energy $i$

$C_{i}$ - The carbon emissions coefficient from fossil fuel

The carbon emissions coefficient data is as follows from energy institute of national development and reform commission.

Table 1 The carbon emissions coefficient of fossil fuel

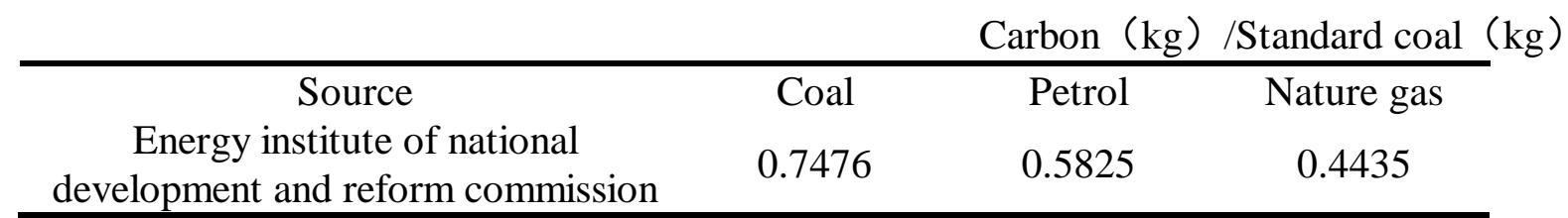

\section{Relationship between carbon emissions and transportation industry}

\section{Research methods and ideas}

China's carbon emissions can be divided into different sections according to the growth rate figure and then using correlation analysis and regression analysis to study the relationship between carbon emissions and freight turnover in order to get the relationship between carbon emissions and transportation industry.

\section{Correlation analysis}

We used the time series data from 1982 to 2014. The energy consumption data is from China Energy Statistical Yearbook,2015, the function is to estimate the carbon emissions by formula 1. The development situation of transportation industry based on the quantity of freight turnover, it's data from China Statistical Yearbook, 2015\&2001.The carbon emissions growth rate line chart is as follows:

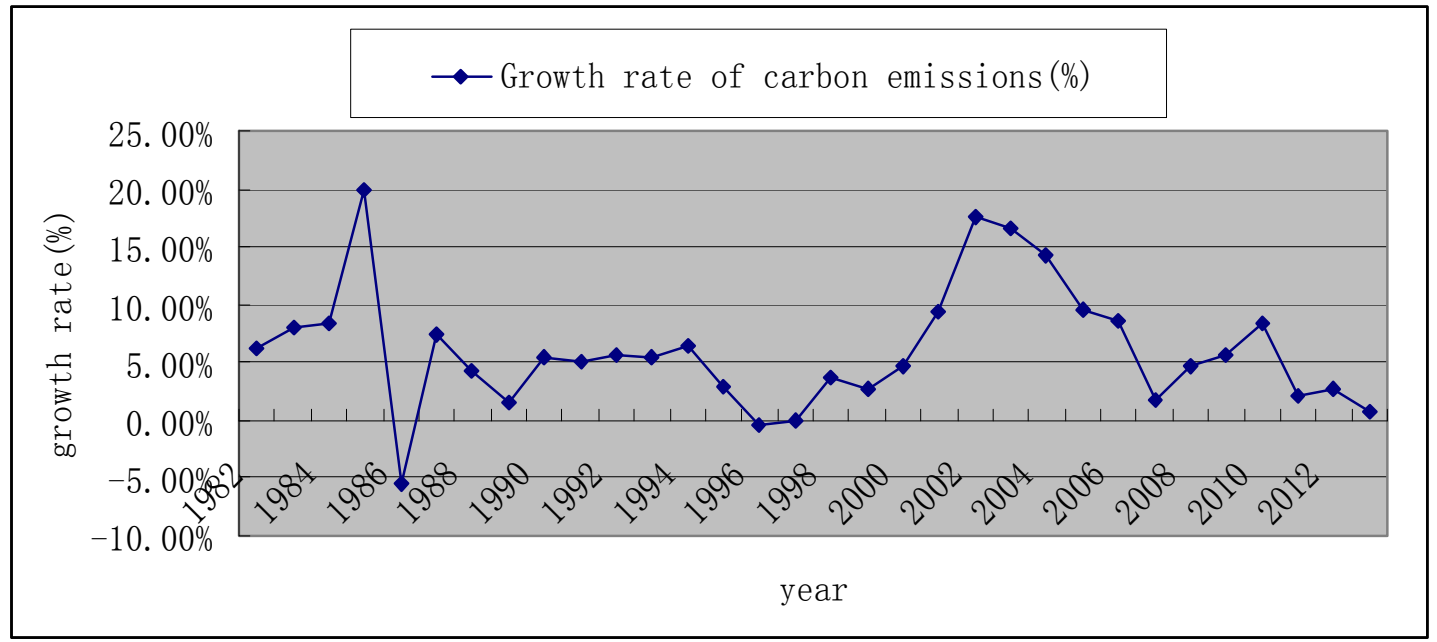

Fig.1 The line chart of carbon emissions growth rate 
The freight turnover growth rate line chart is as follows:

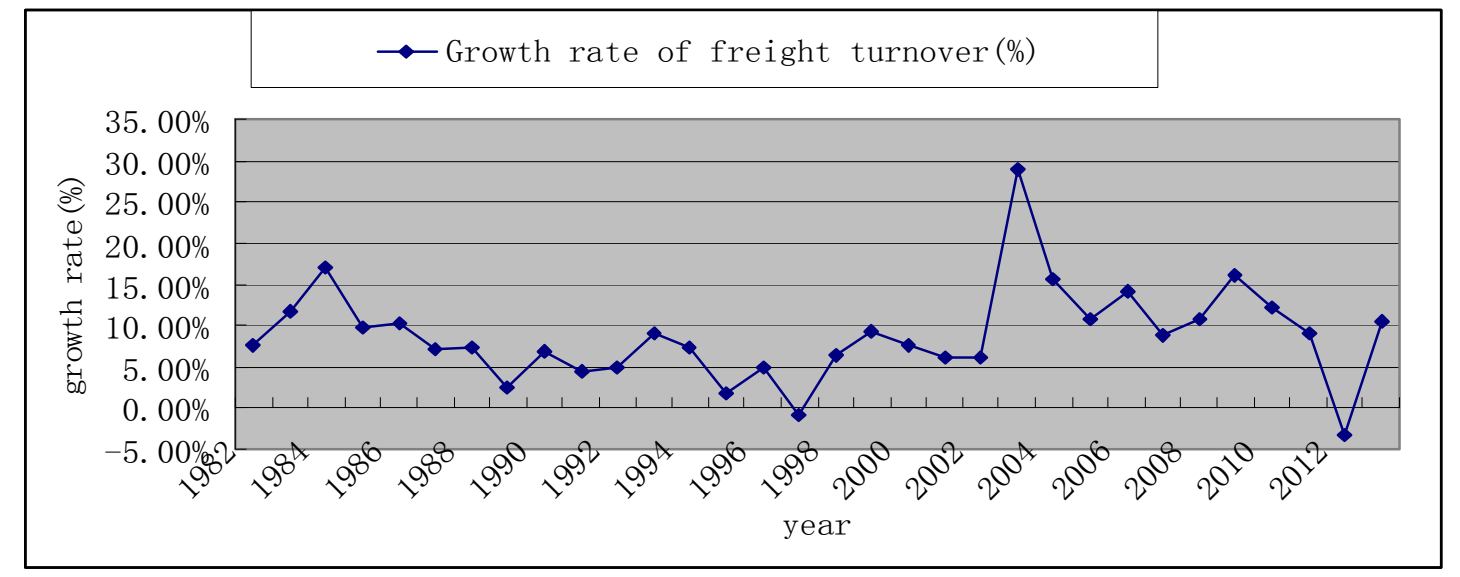

Fig.2 The line chart of freight turnover growth rate

China's carbon emissions periods can be divided into 3 sections according figure 1 . The carbon emissions was accelerating from 1983 to 1988. From 1989 to 2004 , it's growth is stable. After 2005 the growth was decelerating.

For transportation industry, from 1983 to 1988 , the freight turnover growth rate was accelerating and it's average growth rate $(9.09 \%)$ is larger compared with carbon emissions average growth rate (7.53\%). From 1989 to 2004, the trend of vibration is different, the freight turnover growth rate is stable, it's average rate $(5.97 \%)$ is larger than the carbon emissions average growth rate $(3.28 \%)$. After 2005 , the freight turnover growth rate is decelerating, but the average growth rate $(13.26 \%)$ is the largest one among these 3 periods of time, at the same time carbon emissions growth rate also is decelerating, the average growth rate $(8.33 \%)$ also is the largest one.

In conclusion, the freight turnover growth rate is larger than the carbon emissions growth rate, and the relationship between freight turnover and carbon emissions is obvious. We use correlation analysis to analyse the relationship in these 3 periods time. The result is as follows.

\section{Table 2 The relationship between carbon emissions and freight turnover} In different periods of time

\begin{tabular}{cccc}
\hline Period of time & Section 1 & Section 2 & Section 3 \\
$(1980 \sim 1986)$ & $(1987 \sim 2002)$ & $(2003 \sim 2012)$ \\
$\begin{array}{c}\text { Correlation } \\
\text { coefficient }\end{array}$ & 0.9738 & 0.9767 & 0.9771 \\
\hline
\end{tabular}

From the table 3 we can know that the correlation coefficient is increasing gradually. The correlation coefficient is positive, it proved transportation industry is one of the main industries which caused carbon emissions. But we don't know the specific degree caused by freight turnover, so it is necessary to use regression analysis.

\section{Regression analysis}

Regression analysis is a method to analyse relationship among different variables. According to the number of variable, it can be dividend into one element regression analysis and multiple regression analysis.

In this article, we applied one element regression analysis on the study. The independent variable is freight turnover, the dependent variable is carbon emissions. The results from SPSS 19.0 are as follows.

Table 3 The overall model summary

\begin{tabular}{|c|c|c|c|c|}
\hline Model & $\mathrm{R}$ & $\mathrm{R}^{2}$ & Adjusted R squared & SEE \\
\hline 1 & $.982^{\mathrm{a}}$ & .964 & .963 & 1.103645122174 \\
\hline
\end{tabular}


Table 4 The analysis of Variance

\begin{tabular}{|l|l|c|c|c|c|c|}
\hline \multicolumn{2}{|c|}{ Model } & $\begin{array}{c}\text { Sum of } \\
\text { squares }\end{array}$ & df & $\begin{array}{c}\text { Mean } \\
\text { square }\end{array}$ & F & Sig. \\
\hline \multirow{4}{*}{1} & Regression & 1016.903 & 1 & 1016.903 & 834.874 & $.000^{\text {a }}$ \\
\cline { 2 - 8 } & Residual & 37.759 & 31 & 1.218 & & \\
\cline { 2 - 8 } & Total & 1054.662 & 32 & & & \\
\hline
\end{tabular}

Table 5 Total coefficient

\begin{tabular}{|c|c|c|c|c|c|c|}
\hline \multicolumn{2}{|c|}{} & \multicolumn{2}{|c|}{$\begin{array}{c}\text { Unstandardized } \\
\text { coefficients }\end{array}$} & $\begin{array}{l}\text { Standard } \\
\text { coefficient }\end{array}$ & & \\
\cline { 3 - 5 } \multicolumn{2}{|c|}{ Model } & B & Standard error & Trial version & t & Sig. \\
\hline 1 & (Constant) & 3.697 & .303 & & 12.214 & .000 \\
\cline { 2 - 6 } & $\begin{array}{l}\text { Freight turnover (Million } \\
\text { ton kilometers ) }\end{array}$ & 1.268 & .044 & .982 & 28.894 & .000 \\
\hline
\end{tabular}

From these results we can get the formula for carbon emission as follows:

$C=3.679+1.268 \times k^{i}$

$C$ - Carbon emissions

$F$-Freight turnover

This formula illustrates that if freight turnover increased 100 million ton kilometers, as a result carbon emissions would increase 1.268 tons.

The results from one element regression analysis applied in different periods of time are as follows.

Table 6 The result from one element regression analysis applied in different periods of time

\begin{tabular}{|c|c|c|c|c|}
\hline & $\begin{array}{c}\text { Section } \\
1\end{array}$ & Section 2 & Section 3 & Total \\
\hline Correlation coefficient & 974. & 0.977 & 0.977 & 0.982 \\
\hline Goodness of fit & $948^{0 .}$ & 0.954 & 0.955 & 0.964 \\
\hline Adjusted goodness of fit & $938^{0 .}$ & 0.951 & 0.949 & 0.963 \\
\hline Standard error of estimation & $198^{0 .}$ & 0.306 & 0.798 & 1.104 \\
\hline Variance analysis & 0 & 0 & 0 & 0 \\
\hline constant & $003^{1 .}$ & 2.758 & 8.467 & 3.697 \\
\hline Freight turnover coefficient & $\begin{array}{r}2 . \\
448 \\
\end{array}$ & 1.567 & 0.880 & 1.268 \\
\hline
\end{tabular}

Not only the the overall regression analysis, but also the analysis applied in different periods of time, the results are statistical significance. All the goodness of fit are about 0.95 , it illustrates that the models are fit to estimate carbon emissions. The freight turnover coefficient is decreasing, it illustrates that the carbon emissions' change is less than before with the per unit change of freight turnover. 


\section{Conclusion}

(1) To analyse China's carbon emissions in different periods of time since 1982, carbon emissions growth rate can be divided into 3 sections, including accelerating growth section, stable growth section and decelerating growth section. At the same time, the changing trend of transportation industry is similar to carbon emissions, and the growth rate is larger than carbon emission.

(2) The application of correlation analysis used for studying the relationship between freight turnover and carbon emissions show the whole correlation coefficients near 1, it illustrates that there is a high linear correlation between transportation industry and carbon emissions.

(3) Through the results from one element regression analysis applied in different periods of time, we get the conclusion that carbon emissions contributed by transportation industry is less than before gradually.

(4) Also the growth rate of carbon emissions is decelerating, the growth rate of transportation industry is the same. The focus of future research is how to keep the growth rate of transportation industry stable while reducing the carbon emission.

\section{References}

[1] China Energy Statistical Yearbook (1982-2014) [M].2015

[2] Zhao Zongjian. Construction of urban low carbon transportation system [D]. Xi'an: Master's degree thesis of Chang'an University, 2012

[3] Alan McKinnon.CO2Emissions from Freight Transport in the UK[J].2007

[4] Pascal Poudenx. The effect of transportation policies on energy consumption and greenhouse gas emission from urban passenger transportation July 2008 901-909 Pages.

[5] FANG. A. A discrete-continuous model of households'vehicle choiceand usage with an application to the effects of residential density [J].Transportation Research B 2008 736-758. 42:

[6] Su Fengming The concept of low-carbon transport, and the way to realize [J]. integrated transport. 2010, 5: 13 17

[7] Chen Fei, Zhu Dajian. City low carbon traffic model, current situation and strategy of city planning [J]. journal, 2009

[8] Li Jian, Zhou Hui. The carbon emission intensity and industrial structure China association analysis [J]. China population resources and environment, 2012

[9] Xu Guoquan, Liu Zeyuan, Jiang Zhaohua. Chinese decomposition model and Empirical Study of carbon emissions: 1995 - 2004[J]. Chinese population resources and environment, 2006,

[10] Zhang Lei, Huang Yuan Zhejiang, Li Yanmei, et al. China pattern change of regional carbon emissions and emission reduction: a path analysis [J]. Resources science, 2010, 32 (2): 211 - 217

[11] Energy institute of the national development and Reform Commission. Energy and carbon emission scenarios of sustainable development Chinese analysis comprehensive report [R] 2003 